\title{
Saúde mental e automação: a propósito de um estudo de caso no setor ferroviário 1
}

\author{
Mental health and automation: remarks on a case \\ study in the railroad industry 1
}

Edith Seligmann-Silva 2

\footnotetext{
${ }^{1}$ Esta pesquisa teve o apoio do NPP - Núcleo de

Publicações e Pesquisas da EAESP/FGV.

2 Escola de Administração de Empresas de São Paulo, Fundação Getúlio Vargas. Av. 9 de Julho 2029, São Paulo, SP 01313-902, Brasil.
}

\begin{abstract}
This article focuses on some relations between mental health and current technical, organganizaizational, and contextual changes in work. The paper presents some features of a case study, examining the impacts of the work situation in a railroad company on traffic controllers and conductors of a computorized, automatedded system. The article also discusses the implications for the safety of the system as a whole, including passengers.

Key words Mental Health; Railroads; Automation; Worker's Health

Resumo O propósito deste trabalho é enfocar algumas inter-relações entre Saúde Mental e as transformações contemporâneas do trabalho pelas mudanças técnicas, organizacionais e contextuais. Apresenta algumas características em um estudo de caso. O artigo examina os impactos da situação de trabalho em uma empresa ferroviária sobre controladores e maquinistas de um sistema computadorizado e automatizado. As implicações para a segurança de todo o sistema, inclusive para os passageiros, são também apontadas e discutidas.

Palavras-chave Saúde Mental; Ferrovias; Automação; Saúde do Trabalhador
\end{abstract}




\section{A área de saúde mental no trabalho (SMT) em um mundo em transformação}

As transformações organizacionais e técnicas do trabalho vêm se acelerando e assumindo configurações novas não apenas em decorrência do progresso científico e dos avanços tecnológicos. No bojo da globalização intensificada nas últimas décadas, poderosas forças econômicas e políticas presidem a estas transformações e ao modo diferenciado pelo qual estão tendo lugar nas várias regiões e países do mundo. A inter-relação trabalho/saúde acompanha estas mudanças, transformando-se também. Os processos que atingem a saúde mental ocupam um importante espaço dentro desta dinâmica.

As repercussões do trabalho na vida mental, embora estudadas há muito tempo, apenas em época relativamente recente passaram a receber alguma atenção na formação dos profissionais de saúde e nas reuniões científicas. Pesquisas sobre o assunto chegaram a ter resultados que foram considerados propriedade e segredo de empresas que as encomendaram nas primeiras décadas deste século. Nunca foram publicadas, talvez pelo temor dos reflexos sociais destas descobertas (Collins, 1969).

A importância das interações entre os processos de transformação técnica e os processos sociais foi objeto de um dos últimos escritos do filósofo, médico e sociólogo Norbert Elias, um importante pensador do nosso tempo (Elias, 1995). O autor destaca a imprevisibilidade das dinâmicas sociais mediadas pelas descobertas científicas que geram as tecnologias incorporadas à indústria, aos transportes, às comunicações, aos serviços em geral e ao cotidiano humano. Na análise de Elias, a tecnização (technization) repercute na civilização, atingindo de modo especial também os diferentes territórios e padrões da vida relacional. Os modos de viver e todas as interações humanas são atingidos por estas transformações. Incluemse, neste caso, desde as formas de produção de bens materiais e de serviços, até as relações humanas nos mais diferentes âmbitos - do internacional ao comunitário -, alcançando os ambientes de trabalho e a família. Os indivíduos e os vínculos afetivos também estão envolvidos neste processo de mudanças profundas. O modo como indivíduos e mentalidades se alteram nestes processos nem sempre corresponde a avanços de civilização. Para Elias (Elias, 1995), o conceito de civilização é tomado como equivalente a processo social direcionado para o pólo do bem e da vida, e o movimento das transformações pode conduzir tan- to a aperfeiçoamentos de civilização, quanto aos retrocessos que o autor denomina descivilização (decivilization).

O trabalho tem sido identificado como um importante mediador entre diferentes instâncias sociais e a saúde humana, em processos que podem repercutir favorecendo ou prejudicando coletividades e os atores individuais de quaisquer tipos de atividade produtiva. O trabalho, portanto, pode ser fonte de fortalecimento ou de desgaste para a saúde geral.

Refletindo em correlação ao pensamento de Elias (1995), poderíamos dizer que, no conjunto das transformações materiais e sociais que envolvem os seres humanos, a partir do mundo do trabalho, é possível encontrar tendências ora civilizatórias, ora descivilizatórias. Utilizamos aqui a expressão "a partir do mundo do trabalho" porque, além do que ocorre no ambiente onde se realizam as atividades, é necessário considerar a vida laboral em seus reflexos e desdobramentos no cotidiano extratrabalho, desdobramentos estes que apresentam características especiais quando o trabalho é efetivado dentro dos novos paradigmas organizacionais que prevalecem na atualidade.

A análise das situações de trabalho constitui o foco central nas pesquisas de campo em SMT. A organização do trabalho, que inclui, em seus múltiplos aspectos, desde as formas de gestão até a organização temporal do trabalho e as relações inter-hierárquicas e interpessoais, vem ocupando um lugar central nos estudos em que se busca entender as vinculações entre saúde mental e trabalho, para, assim, identificar perspectivas preventivas. As situações de trabalho, compreendem, além dos aspectos organizacionais, os aspectos do ambiente físico, químico e biológico, que tradicionalmente eram os únicos estudados em Medicina do Trabalho; analisam ainda as múltiplas interações existentes, por um lado, entre os componentes internos destas situações de trabalho e, pelo outro, as conexões destes componentes ao contexto sócio-político e econômico. A dimensão cultural vem recebendo grande atenção nestes estudos, nos quais a antropologia do trabalho examina valores, atitudes, crenças e hábitos, que permitem compreender, muitas vezes, o sentido assumido pelo trabalho para aqueles que o realizam. Este sentido é a chave para um outro entendimento, que interessa simultaneamente aos especialistas da saúde mental e aos administradores, pois tanto a qualidade da vida mental, quanto a adesão criativa ao trabalho irão depender do mesmo.

Os estudos referentes à Saúde Mental no Trabalho exigem sempre que se considere o 
contexto político e sócio-econômico. Por conseguinte, nas pesquisas de campo, torna-se imprescindível investigar as interações entre as condições gerais de vida e as situações de trabalho.

\section{Correntes teóricas}

As repercussões do trabalho sobre a saúde mental têm sido estudadas em diferentes abordagens, com base em correntes teóricas originadas em diferentes disciplinas. Podemos, então, distinguir três correntes:

a) A que se fundamentou em estudos psicofisiológicos, centralizando-se no conceito de estresse (work-stress). Sob esta perspectiva, foram realizadas múltiplas pesquisas pioneiras dentro da temática, a qual, até hoje, continua oferecendo embasamentos para estudos epidemiológicos.

b) A corrente dos pesquisadores que integraram o referencial psicanalítico à análise das vivências humanas conectadas ao trabalho. No Brasil, os estudos mais divulgados desta corrente são os do grupo francês, que desenvolve atualmente o campo teórico que seus integrantes denominaram Psicodinâmica do Trabalho, o qual emergiu de estudos anteriores de Psicopatologia do Trabalho, realizados por esta mesma equipe, para a qual o conceito de sofrimento mental havia sido formulado por Dejours, desde 1980 (Dejours, 1993).

c) As Ciências Sociais assumem centralidade nos enfoques de outros pesquisadores, para os quais os agravos mentais originados pelo trabalho passam pela dinâmica da dominação, precisando ser analisados sob a ótica das relações de poder. Tais agravos seriam, portanto, o resultado de perdas, que configurariam um desgaste mental. Estas perdas podem ser concretas, potenciais ou simbólicas. Podem ser de natureza biológica, psíquica, ou social, e geralmente abrangem articuladamente estas três instâncias, mesmo que a repercussão orgânica seja menos visível a curto prazo.

Tomemos o efeito causado à identidade social e pessoal decorrente de um acidente ou patologia originada no trabalho para exemplificar a complexidade do desgaste, que é ao mesmo tempo psicológico, físico e social. Por outro lado, existe a constatação de que os processos em que se constroem os danos mentais muitas vezes abrangem as três instâncias. Por exemplo, a fisiologia e o psiquismo são concomitantemente envolvidos por experiências em que se acumula a fadiga ou em que surgem emoções penosas, desdobrando-se estas alte- rações em repercussões sociais - retraimento social, conflito ou alienação sócio-política, por exemplo. Deste modo, o conceito de desgaste pode assumir o caráter de uma opção conceitual integradora (Seligmann-Silva, 1994).

Vale mencionar que as três correntes citadas têm apresentado diferentes desdobramentos. Não obstante, podem ser estabelecidas convergências entre as mesmas, especialmente na medida em que podem ser percebidas correspondências entre suas descobertas de pesquisa. É o que acontece à identificação não só da importância psicopatogênica de certas constelações situacionais e interações, como também das repercussões clínicas e sociais das mesmas. Encontramos, assim, a descrição de agravos cujas características clínicas são iguais ou muito semelhantes, embora venham recebendo denominações distintas e aderidas aos respectivos quadros teóricos de referência (Seligmann-Silva, 1995a).

Na transição entre saúde e doença, pode-se reconhecer um estágio de mal-estar e de tensão que ainda não pode ser considerado patologia, mas que, não sendo encontradas alternativas para superar a dinâmica biopsicossocial que origina tal perturbação, poderá vir a assumir configuração de quadro mórbido. Este estágio, nos estudos iniciais da psicofisiologia do trabalho, era simplesmente englobado pela temática referente à fadiga. A complexidade desta etapa, entretanto, segundo estudos posteriores, transcende os fenômenos da fadiga e ela tem sido estudada por diferentes pesquisadores, que lhe têm conferido denominações diversas: sofrimento, estresse leve ou simplesmente estresse. Em Saúde Coletiva, o conhecimento deste estágio de transição assume, evidentemente, enorme importância para as práticas preventivas. $\mathrm{O}$ desafio preventivo tornase tanto maior à proporção que passa a exigir um diálogo cada vez mais permanente entre os profissionais da área de saúde e os responsáveis pelo planejamento e pela administração no mundo do trabalho.

É interessante assinalar a aproximação que vem se fazendo entre a Sociologia do Trabalho e a SMT, observando que essa aproximação parece carregar consigo um importante estímulo para aumentar a interlocução entre as três correntes mencionadas. Isto porque os estudos da Sociologia do Trabalho vêm tomando rumos que integram:

a) aspectos de psicologia cognitiva - presentes também nos estudos mais atuais da "corrente do estresse";

b) preocupações com o papel da dimensão psicoafetiva e da intersubjetividade na mobili- 
zação subjetiva da inteligência e da cooperação criativa nas equipes de trabalho, enfocando assim processos anteriormente analisados principalmente pela corrente psicodinâmica; c) análises da dominação nos contextos de trabalho e das formas sutis que esta dominação assume na modernidade dos sistemas computadorizados e automatizados. Tais estudos articulam-se, evidentemente, com a corrente que encontrou no materialismo histórico o referencial teórico para o estudo do desgaste.

Outras convergências podem ser assinaladas atualmente. Assim, a Antropologia do Trabalho, a Psicologia Social e a Lingüística trazem riquíssimas contribuições à SMT, especialmente na medida em que permitem ampliar o entendimento de aspectos tais como a formação de valores e significados relativos ao trabalho, nas várias culturas e subculturas. Da mesma forma, determinados estudos de Ética e de Filosofia Política se aproximam da SMT ao analisarem as tendências atuais da ética no trabalho. Por outro lado, na área da Educação, estudos que também examinam os riscos e equívocos do reducionismo tecnicista observado no ensino formal passam a dialogar com a SMT (Ferretti et al., 1994; Bruno, 1996).

O desafio epistemológico que nasce destas novas aproximações nos conduz a identificar a necessidade de um campo transdisciplinar para o prosseguimento destes estudos. Acreditamos, entretanto, que a construção deste campo já foi iniciada e pode ser reconhecida quando examinamos o modo como investigadores de diferentes áreas do conhecimento começam a construir uma linguagem comum em atividades de pesquisa e em reuniões científicas voltadas para a temática (Matrajt, 1994; Dejours, 1995; Seligmann-Silva, 1994).

\section{Algumas descobertas a considerar em saúde mental e no trabalho sofisticado}

O trabalho diante de telas de vídeo tem sido amplamente estudado, bem como as atividades em sistemas automatizados tradicionais aqueles em que o empregado é levado a assumir uma posição de mero vigilante do sistema, sem interação inteligente com o mesmo. Seria impossível discorrer aqui sobre tudo o que já foi estudado a respeito do cansaço mental, das vivências de monotonia, da sonolência e de tantos outros aspectos bastante divulgados em relação a estas ocupações. O esvaziamento de conteúdo é sempre vivenciado como empobrecedor e desqualificante nesta modalidade de automatização. Contudo, quanto maior o grau de controle sobre o operador - derivado, às vezes, de dispositivos inseridos no próprio sistema técnico -, maior o mal-estar, que pode assumir a configuração de vivências de insegurança ou mesmo de perseguição.

Procuraremos a seguir, examinar sinteticamente algumas das descobertas relevantes que, na atualidade, configuram novos desafios aos pesquisadores da SMT e de áreas correlatas. Algumas delas apontam para novos enfoques do trabalho computadorizado e da automação.

\section{As defesas psicológicas socialmente articuladas}

O estudo destas defesas foi consideravelmente desenvolvido por Dejours e outros pesquisadores do grupo francês da Psicopatologia do Trabalho, desdobrando-se atualmente nas pesquisas que eles desenvolvem na área que passaram a denominar Psicodinâmica do Trabalho (Dejours, 1993).

Os pactos e modos coletivos de negar, reprimir ou deslocar sentimentos, tais como medo e repugnância, situam-se nesta abordagem.

As implicações que emergem destes estudos para a saúde geral, para a saúde mental e para a própria segurança do trabalho foram bastante analisadas pelo grupo francês e por pesquisadores de outros países, que assumiram as propostas conceituais de tais abordagens. Assim, os poderosos mecanismos defensivos coletivos - que, segundo Dejours, assumem o feitio de uma verdadeira ideologia atuam ao lado das defesas psicológicas individuais, para tornar suportável o trabalho perigoso e, de maneira mais geral, o trabalho gerador de sofrimento psíquico. Ao bloquearem a percepção crítica dos aspectos potencialmente agressivos da situação de trabalho, estes mecanismos colocam também obstáculos nos caminhos para a organização de enfrentamentos conscientes.

\section{Fenômenos estudados nas dinâmicas intersubjetivas e interativas das situações de trabalho sofisticado}

Trata-se aqui de descobertas decorrentes da convergência de estudos de sociologia, assim como de psicologia social e do trabalho, as quais estão revelando o profundo inter-relacionamento de questões que passaram a interessar concomitantemente cientistas sociais, profissionais de saúde e administradores de empresas. Estas questões dizem respeito à qualificação e à construção de competências para o 
trabalho variado e complexo, em formas nas quais se desenvolva cooperação e criatividade. Trata-se, portanto, de saber como o trabalho pode ser feito de um modo ao mesmo tempo inteligente e harmonicamente interativo. Envolve, por um lado a dimensão subjetiva, na qual sentimentos e inteligência de cada indivíduo interatuam, e, por outro, as comunicações e interações entre sujeitos.

Zuboff (1988) coloca a comunicação interpessoal como aspecto fundamental para a construção de um sentido que será percebido pelo conjunto e por cada um dos integrantes do grupo de trabalho. A autora considera a importância da dinâmica do reconhecimento e da dimensão ética dentro deste processo. $\mathrm{O}$ objeto destas pesquisas de Zuboff não é a saúde mental, mas, sim, a informatização em vinculação a um conjunto de questões referentes à gestão, à sociabilidade e à qualidade da comunicação existentes em empresas que haviam implantado sistemas informatizados, alguns dos quais acompanhados por automação industrial. As colocações desta autora coincidem, entretanto, com as que Dejours veio a publicar nos anos seguintes (Dejours, 1993, 1995; Dejours et al., 1994), em estudos que não estavam centrados na questão da informatização, e, sim, na da mobilização subjetiva nas situações de trabalho.

\section{Conteúdos psicossociais da qualificação}

A idéia de que a qualificação desejável para a atividade em sistemas informatizados depende apenas de ampliação de conhecimentos teóricos e de formação técnica está ultrapassada. Sabemos hoje que as habilidades intelectuais necessárias para que a informatização seja utilizada em todos os seus potenciais exige não apenas aprendizagem de teorias e de técnicas, mas está vinculada a uma sociabilidade na qual se elaborem comunicações significativas. A qualificação em sua articulação à construção do sentido só é possível em contextos de trabalho nos quais a dimensão ética esteja assegurada simultaneamente à preservação dos espaços de relacionamento significativo e de autonomia do pensamento (Zuboff, 1988; Böhle \& Milkau, 1988; Lojkine, 1995).

A tese de que elevação dos níveis de qualificação corresponderia a menor desgaste e, portanto, a melhores condições de saúde mental prevaleceu por bastante tempo, tendo, no entanto, passado a ser contestada com base em pesquisas realizadas na Alemanha. Marstedt (1994) realiza a revisão dos estudos que descrevem distúrbios psicológicos e relacionais em áreas automatizadas. O autor analisa os aspectos organizacionais existentes nas empresas estudadas e identifica conceitos e práticas de racionalização que são responsáveis pelo aumento das cargas mentais de trabalho, condicionando riscos para a saúde. Tais sobrecargas diriam respeito principalmente à complexidade das atividades, à exigência de polivalência, a elevadíssimas cargas psicoafetivas (autocontrole emocional exacerbado; exigências de perfeição no desempenho; alto nível de responsabilidade; insegurança quanto à manutenção do emprego e às perspectivas de carreira), e, a múltiplos tipos de pressão temporal (prazos, ritmos, etc.). Marstedt demonstra, ainda, que a política de saúde ocupacional precisa estar atenta para as implicações perversas dos novos conceitos de racionalização adotados pelas empresas. Além de mostrar outros aspectos relevantes,o autor examina as tensões resultantes da percepção, pelos assalariados qualificados, das incertezas presentes no âmbito macroeconômico e nas competições entre empresas. No que se refere a esta incerteza, Mattoso (1995) realizou análise semelhante na realidade brasileira.

Identidade no "trabalho moderno". O estudo da identidade em suas vinculações ao trabalho integra diferentes perspectivas

Em primeiro lugar, deve ser lembrado que o trabalho é um contexto formador da identidade em processo. É o reconhecimento que faz a articulação entre a construção da identidade e os processos sociais (Sainsaulieu, 1988), sendo também aspecto essencial na construção da identidade social e, ao mesmo tempo, nos processos de saúde mental. A conexão entre identidade e reconhecimento tem proporcionado o entendimento de importantes aspectos da psicopatogênese em situações de trabalho, quando a falta de reconhecimento deflagra frustrações ou vivências de autodesvalorização, podendo ainda mobilizar sentimentos como raiva ou o medo de perder o emprego.

Em segundo lugar, devemos considerar certos fenômenos enfocados pela antropologia do trabalho - como o da antropomorfização do computador, dos robôs e de outros equipamentos sofisticados, que apresentam impactos para a identidade e, por conseguinte, para o psiquismo. Trata-se de repercussões que geralmente atingem a sociabilidade. A situação mais freqüente é aquela em que o sistema - ou mesmo o computador - passa a ser percebido como um "ser" perfeito e poderoso. Um ser que pode despertar vivências de inferiorização e 
dependência, levando à passividade. Em outros casos, a máquina inteligente pode tornarse modelo de comportamento racional, em que os sentimentos passam a ser vistos como "erros". Isolamento social ou conflitos interpessoais - freqüentemente na família - podem ser originados pela irritação com a "lentidão" ou "ineficácia” das pessoas, comparativamente à máquina ou ao sistema "perfeitos” (Rebecchi, 1990; Rocha, 1996).

Em terceiro lugar, vale assinalar, ainda, a íntima e complexa conexão existente entre identidade, subjetividade e as dinâmicas que atuam nos processos psicossomáticos e psicopatológicos. Tendo sido bem analisada em diferentes perspectivas por vários autores, dentre os quais podemos destacar Marty (1976, 1980), esta conexão abre-se atualmente à investigações em SMT, no momento em que as transformações no mundo do trabalho derivam para intensas repercussões nas identidades. Especialmente os estudos que estão revelando e esclarecendo mediações antes desconhecidas na inter-relação trabalho/saúde mental - como a aceleração mental, as atividades subjetivantes, a alexitimia, emergentes nos modernos contextos de trabalho - trazem novas perspectivas para a compreensão da gênese de problemas do âmbito da saúde coletiva, como a escalada de mal-estares e de transformações da sociabilidade que atingem o cotidiano daqueles que exercem suas ocupações em contextos computadorizados.

As pressões organizacionais voltadas para a excelência e seus impactos na subjetividade e nas relações interpessoais

Estas pressões estão geralmente associadas ao processo de modernização em que vêm sendo implantadas as novas tecnologias de base microeletrônica. As repercussões das mesmas em termos de desestruturação subjetiva e risco para a saúde mental são de tal monta e complexidade, que não será possível tratar do assunto aqui, o qual já mereceu amplos estudos de outros autores e também da nossa parte (Aubert \& Gaulejac, 1991; Marstedt, 1994; Medeiros, 1995; Seligmann-Silva, 1995b).

\section{A automação ferroviária: observações a partir de um estudo de caso}

Os estudos brasileiros que dizem respeito à Saúde Mental no Trabalho em áreas onde os computadores e a automação estão penetrando começaram a desenvolver-se nos últimos anos, especialmente em atividades de processamento de dados e de automação industrial (Fernandes, 1992; Rocha, 1989, 1996; Fischer, 1990; Tittoni, 1994). Estudos centrados no trabalho bancário também enfocaram o assunto (Silva Filho, 1994; Jinkings, 1995; Seligmann-Silva et al., 1985), mas existe uma outra área onde a automação está avançando - a dos transportes.

A modernização técnica dos serviços de transporte coletivo suscita uma premente necessidade de obter maior conhecimento sobre as repercussões da introdução de mudanças tecnológicas e organizacionais para a saúde mental dos operadores destes sistemas. Tal assunto incorpora a confiabilidade em um sistema cuja segurança diz respeito à vida das extensas populações que são usuárias destes transportes.

Estudos referidos a sistemas de transporte coletivo que estão absorvendo novas tecnologias também passaram a ocorrer no Brasil ao longo da última década. Podem ser assinalados, por exemplo, diferentes pesquisas voltadas para operadores de trem metroviário nos Estados de S. Paulo e Rio de Janeiro (Seligmann-Silva et al., 1986; Jardim, 1994).

Com base em uma pesquisa realizada em uma empresa ferroviária brasileira, a qual havia passado recentemente pela implantação de um sistema operacional automatizado, apresentaremos a seguir algumas observações concernentes ao tema da inter-relação automação/saúde mental.

\section{A pesquisa}

A investigação foi em grande parte estimulada pela atual problematização da escalada de tecnologias avançadas em contextos sócio-políticos e empresariais, marcados por dependência econômica e por culturas políticas vinculadas a experiências históricas de dominação prolongada.

Ao formularmos o projeto da pesquisa, em 1988, alguns pesquisadores de outros países apontavam para os riscos humanos envolvidos nas transferências tecnológicas que se faziam de nações de economia central para a Índia e países da América Latina. Nestes, as condições gerais de vida ainda fragilizavam o tecido social, e, ao mesmo tempo, as práticas de gestão e organização do trabalho adotadas pelas empresas não haviam ainda superado o autoritarismo e o taylorismo.

Por outro lado, Foret, em 1987, havia publicado uma ampla revisão a respeito dos transtornos psicológicos e psicofisiológicos verificados em condutores de trem de diferentes paí- 
ses do mundo, identificando a importância dos prejuízos à saúde decorrentes da estrutura temporal das atividades nesta ocupação - regime de turnos alternados, trabalho noturno, jornadas prolongadas, entre outros aspectos examinados por ele. $\mathrm{O}$ autor, entre outras conclusões formuladas valendo-se desta revisão, assinalava a constatação da ausência de estudos referentes à psicopatologia conectada a estas stiuações de trabalho na condução de trens.

Deste modo, nosso projeto surgiu motivado pelo interesse em investigar de que modo, no Brasil, a modernização do sistema ferroviário estaria repercutindo sobre a saúde mental dos operadores deste sistema, pretendendo detectar, conjuntamente, repercussões psicossociais articuladas a outros aspectos da situação de trabalho - como o trabalho em turnos alternados -, e também identificar eventuais implicações das situações estudadas para a segurança do sistema ferroviário. Consideramos, ainda, o interesse em verificar em que medida os problemas de saúde mental eram percebidos e alvo de atenção por parte do serviço de saúde da própria empresa. Neste artigo, procuraremos nos centrar nas repercussões do tipo de modernização que foi implantado.

Escolhemos duas categorias de profissionais para o estudo:

a) Os controladores, que são os técnicos que trabalham em sala do centro de controle operacional (CCO), acionando, acompanhando e orientando a circulação dos trens através do sistema computadorizado que conecta e integra o complexo ferroviário (linhas, trens, estações e energização), e que simultaneamente comunicam-se por meio de rádio, telefone, ou até mesmo - para algumas estações - por telecomandos. A escolha de tais profissionais ocorreu por sabermos de sua posição no coração do sistema operativo, tendo responsabilidades imensas com os equipamentos e com as vidas de passageiros e de outros funcionários, inclusive dos maquinistas, associando-se a isso tudo um trabalho dominantemente mental, realizado em regime de turnos alternados.

b) Os operadores de trem (maquinistas), que, estando em interação direta com os novos dispositivos técnicos, também tiveram, segundo nossa suposição inicial, confirmada pelo estudo bibliográfico (Bouvier, 1985), aumentadas suas cargas mentais de trabalho, além de, com a instalação dos novos equipamentos, terem passado a ter a estruturação de suas atividades profundamente alterada. Por outro lado, sabíamos que enfrentavam jornadas de trabalho nem sempre regulares, trabalhando também em turnos alternados.

\section{- As atividades desenvolvidas ao longo da pesquisa}

Optamos por uma metodologia qualitativa. A pesquisa de campo desenvolveu-se ao longo de três etapas. Apresentamos a seguir sucintamente as principais atividades e procedimentos adotados:

a) Primeira etapa: exploração do campo e construção dos roteiros de entrevista para maquinistas e controladores. Nesta fase, foram realizadas também entrevistas com especialistas que haviam participado do planejamento e implantação do sistema automatizado.

b) Segunda etapa: período do trabalho de campo, quando foram registradas as observações realizadas em sala do CCO (Centro de Controle Operacional) e feitas entrevistas semi-estruturadas, grupais e individuais. Foram ainda realizadas observações durante viagens em cabines de trem, em diferentes percursos, ocasiões durante as quais ocorreram também entrevistas informais.

Além das entrevistas com controladores e maquinistas, também foram realizadas entrevistas individuais com gerentes de diferentes posições na hierarquia da área operacional, com um inspetor da área operativa e, também, entrevistas informais no Serviço Especial de Segurança e Medicina do Trabalho (SESMT), com diferentes profissionais. Destacamos a importância de três entrevistas feitas com supervisores do CCO.

Utilizamos um caderno de campo para registro de observações e contatos informais durante nossa permanência nos vários ambientes da empresa em que a pesquisa de campo se desenvolveu.

c) Terceira etapa: organização do material levantado, seguido de análise do mesmo.

Deixou de ocorrer a quarta etapa, que deveria consistir na devolução dos resultados aos pesquisados, em reuniões destinadas também à validação final dos achados e posterior incorporação ao relatório final dos comentários e adendos resultantes. A reestruturação e desmembramento da empresa, que coincidiram com o final da pesquisa, foi uma das principais razões. Assim, apenas foi possível apresentar resultados a alguns dos entrevistados, antes da elaboração do relatório final.

No conjunto, a segunda e a terceira etapa se desenvolveram a partir do segundo semestre de 1990 até o final de 1993, o que permitiu acompanhar diferentes mudanças organizacionais. 


\section{- A ótica da empresa diante do desgaste humano}

As entrevistas que realizamos com especialistas e técnicos que haviam participado do planejamento e execução das inovações revelaram que a questão da segurança sempre foi uma preocupação importante. Entretanto, a vinculação da segurança a aspectos de saúde psicossocial não transpareceu em nenhum dos depoimentos registrados.

As respostas de três gerentes (engenheiros) abordaram aspectos de "capacidade mental", em termos psicológicos, mas sem considerar que exigências elevadas colocadas ao trabalho mental poderiam conduzir a distúrbios da saúde, que, por sua vez, teriam repercussão negativa para a segurança. Ficou evidente que estes planejadores do trabalho não haviam recebido informações sobre os riscos mentais neste tipo de atividades; eles consideravam segurança uma questão de enorme importância, mas viam-na como algo totalmente separado da questão do desgaste humano.

Em primeiro lugar, parecem não ser percebidos aqui os riscos de infligir danos aos próprios portadores da "capacidade humana", porque a imposição de novas exigências baseadas em visões cujos fundamentos são apenas de ordem econômica e técnica implica deixar de lado a necessária análise da complexidade biopsicossocial desta "capacidade humana”. E tal equívoco em verdade traz ameaças de deterioração a esta mesma capacidade, reduzindoa à condição simplificada de "fator humano".

Em segundo lugar, as entrevistas apontam para o desconhecimento, por parte dos entrevistados, de que uma planejada intensificação das atividades poderá superar as possibilidades psicofisiológicas humanas de manter a atenção vigilante, a agilidade de raciocínios e a prontidão para respostas rápidas, necessárias para a segurança do sistema ferroviário.

Discutimos essa questão da "invisibilidade" da inter-relação trabalho/saúde com um técnico da empresa que trabalhara na sala de controle e depois ascendeu funcionalmente, tendo deixado a empresa durante o período em que realizamos a pesquisa. Ele nos ofereceu uma explicação importante, baseado em sua experiência:

"O que acontece é que esperam que quem está diretamente na chefia do CCO se responsabilize pelos problemas de "fator humano" que aconteçam lá, e, inclusive, se um chefe vai levar para o gerente do escalão superior um problema desse tipo, vai ficar mal visto. Vão considerar que ele não está sendo capaz de resolver pro- blemas que são da alçada dele. Daí, até pra não ser prejudicado na própria carreira, não costuma levar o problema lá para cima (para escalões superiores). Às vezes, é claro, isso fica impossível: por exemplo, já aconteceu uma morte em serviço, parece que foi uma espécie de enfarte fulminante que o controlador teve. Morreu em cima da mesa do console! Aí, não dá pra deixar de pensar se esse problema foi ou não de estafa".

A negação de vinculações entre a situação de trabalho e os danos sofridos pela saúde dos controladores aparece, portanto, integrando a cultura da empresa.

Quanto aos controladores, constatamos ainda a existência de uma "cultura do controle”, em que o autocontrole é erigido em valor essencial pelos próprios controladores, passando a assumir importante papel em sua identidade. Eles são aqueles que têm o dever e a responsabilidade permamente de tudo controlar no sistema. A auto-exigência é continuamente realimentada formal e informalmente, a partir de ordens recebidas e dos imprevistos do cotidiano. Os intensos níveis de auto-exigência contribuem de modo importante para que os próprios controladores participem na invisibilização mais prolongada do próprio mal-estar e do desgaste acarretados pelas atividades no CCO. Deste modo, só ao longo do tempo, seus agravos irão eclodir, e, mais freqüentemente, sob expressão somática - como exemplificado possivelmente pelos freqüentes distúrbios digestivos relatados e pela ocorrência de hipertensão arterial em vários dos controladores entrevistados.

No que diz respeito aos maquinistas, a questão se apresenta de maneira diferente. Seria impossível negar a existência de problemas, havendo - conforme as informações obtidas no SESMT - elevada prevalência de alcoolismo entre maquinistas. Entretanto, embora a dependência de bebidas alcoólicas seja reconhecida, a vinculação entre a mesma e a situação de trabalho do maquinista não o é.

Não obstante a falta de dados estatísticos exatos por parte da empresa, o alcoolismo é um dos distúrbios de saúde de maior freqüência nos maquinistas, segundo os entrevistados no SESMT, que desenvolvia atividades terapêuticas, porém não medidas preventivas, que fossem voltadas para modificação de situação de trabalho em relação ao problema.

A existência, na cultura hierárquica, de uma desvalorização marcada por desconfiança por parte dos subordinados - aquilo que De- 
jours denomina "psicologia pejorativa" - parece bastante evidente. Tal fato, em nossa interpretação, possivelmente desempenha importante papel para explicar a extensão do próprio alcoolismo, que em outras pesquisas referentes ao desgaste mental no trabalho surgiu freqüentemente associado a situações em que a dignidade havia sido alvo de agressões (SeligmannSilva, 1994; Matrajt, 1994).

Tivemos informação de que a rejeição para absorver em outras funções os maquinistas afastados de suas funções, não ocorria apenas nos casos de alcoolismo, porém mesmo para portadores de outros problemas, como de hipertensão arterial. A explicação que nos foi dada foi bastante esclarecedora:

"É que, mesmo se ele não beber, vão achar que o problema é esse ou, então, que, de qualquer modo, ele deve ser malandro".

Portanto, de uma forma diferente da verificada em relação aos controladores, constatamos existir também, no caso dos maquinistas, uma negação ocultadora da inter-relação trabalho/saúde. Só que, neste caso, ela é mediada por um preconceito possivelmente relacionado com a desqualificação associada às transformações do sistema, contrastando com outros tempos, em que, portando grande orgulho da profissão, o maquinista era figura socialmente prestigiada.

\section{O conflito entre segurança e velocidade}

O confronto entre as metas segurança e velocidade se estabelece freqüentemente nas situações concretas e assume evidente papel na gênese de altos níveis de tensão emocional.

Vale examinar os componentes deste conflito.

a) Em primeiro lugar, identificamos novamente um componente de ordem cultural, vinculado à imagem de modernidade que a empresa almeja conquistar. Na representação da modernidade, a velocidade é elemento altamente valorizado, especialmente em se tratando de um sistema de transportes.

b) Ainda fortalecendo a idéia de velocidade, ocorrem as pressões cotidianas dos usuários. As expectativas de um sistema cuja eficácia transpareça através da velocidade de seus trens pertencem não só à empresa, mas também aos passageiros. A figura do usuário passa, assim, a suscitar duas questões de peso considerável nas decisões e ações da empresa, por um lado, e nas atitudes e emoções dos maquinistas, por outro. Resultam daí, favorecendo a meta da velocidade, três aspectos distintos:

b.1) Passa a existir um interesse político, por parte da empresa - que é estatal -, de que a po- pulação usuária seja satisfeita em suas expectativas e de que, a todo custo, sejam evitados atrasos.

b.2) Manter a velocidade e, muito essencialmente, evitar atraso são preocupações presentes nos maquinistas, não só por este conhecer a posição da empresa sobre a questão, mas também por um motivo que, em nossa pesquisa, emergiu como fundamental: o temor dos tumultos e agressões de que ele pessoalmente possa ser vítima, causados por usuários que exigem mais velocidade ou que se revoltam diante de atrasos.

b.3) Por parte do maquinista, pode existir ainda algo que foi expresso por vários entrevistados: a legítima preocupação de que os passageiros não sejam prejudicados, em seus empregos, pelos atrasos. Deve aqui ser lembrado que muitas vezes tal situação ocorreu por razões as mais variadas e que a velocidade maior, nestes casos, visa compensar tais demoras.

Vejamos agora os aspectos que favorecem a segurança:

a) Em primeiro lugar, a consciência da responsabilidade com vidas humanas será fator de peso dentro do conflito estabelecido na mente do maquinista.

b) As normas técnicas e os regulamentos, por outro lado, pressionam o maquinista a seguir o que neles está prescrito em relação aos limites de velocidade determinados para os diferentes trechos e situações. Infringindo tais regras, o maquinista correrá o risco de ser submetido a sindicância e responsabilizado por qualquer prejuízo - humano ou material - advindo da quebra destas prescrições formais. Em síntese, poderá receber sanções por quebra da disciplina e ser considerado irresponsável, com risco de suspensão ou mesmo demissão, dependendo da gravidade das conseqüências da infração.

Deste modo, envolvido em tal malha de pressões contraditórias, não é de surpreender que as opções do maquinista em relação ao dilema acima considerado - infringir ou não as determinações atinentes à velocidade - não se façam sem tensão e sofrimento psíquico.

Vale mencionar algumas constatações a respeito das "manhas" que desfazem controles automatizados:

"Existem jeitos de enganar o sistema e andar dando mais velocidade do que a que é comandada por ele" (maquinista).

Outro funcionário nos explicou que estes “jeitos” são denominados "gambiarras" e se constituem segredo profissional dos maquinistas, que ao longo do tempo aprenderam manhas pelas quais podem burlar os controles au- 
tomatizados embutidos no sistema. Conhecem técnicas pelas quais desativam, por exemplo, o funcionamento do dispositivo que faz parar o trem quando a velocidade prescrita é ultrapassada. Deste modo, nas ocasiões de fortes pressões dos usuários em trens atrasados, a velocidade é aumentada. Como a satisfação dos usuários e a imagem construída a partir desta satisfação se constitui interesse relevante para a direção da empresa, nenhuma punição ocorre para o maquinista "se tudo correr bem". Isto é, se a infração não ocasionar nenhum acidente, mesmo sendo descoberta pelos superiores hierárquicos, nenhuma censura costuma ser feita ao maquinista responsável.

Funcionários de diferentes categorias - e não apenas os maquinistas - falaram-nos desta situação dúbia, de "gambiarras consentidas". Tivemos, entretanto, oportunidade de acompanhar um acidente - um choque de trens, com feridos mas sem vítimas fatais -, em que o rumo dos acontecimentos foi outro. Nesse caso, a sindicância efetuada detectou que o choque havia sido provocado porque o maquinista do trem que vinha atrás fizera uma "gambiarra”, de modo que um trem que, por motivos técnicos, havia sofrido atraso e vinha à frente, na mesma linha, sofreu o choque. No processo instaurado, o maquinista estava sendo acusado e existiam altas probabilidades de que seria condenado.

As "gambiarras" relacionadas à burla das velocidades prescritas são de prática bastante comuns, dada a freqüência e intensidade das pressões dos usuários, que, como já foi dito, podem inclusive se tornar violentas. O maquinista, sozinho em sua cabine, pode recorrer apenas ao controlador pelo rádio, para pedir orientação e apoio. A precariedade deste tipo de comunicação, como verificamos in loco, prejudica a clareza da mensagem e agrava a ansiedade. É possível compreender, então, por que o maquinista tantas vezes utiliza seu conhecimento prático, acionando a "gambiarra". Em verdade, ele sabe que, de modo mais geral, tal artifício é encarado de forma condescendente pelas chefias, contanto que "nada aconteça”, pois, se "acontecer" (incidente ou acidente), a "gambiarra" será constatada pela perícia.

$\mathrm{O}$ aspecto mais grave deste tipo de infração decorre não somente do excesso de velocidade, mas, especialmente, do fato de que o mais importante fator de proteção do ATC (Automatic Train Control) - a parada automática do trem em situação de risco - é desativado pela "gambiarra".

É possível que o que acontece nestas situações fique mais claro se utilizarmos alguns tre- chos da entrevista com um dos técnicos da empresa que nos expôs o problema:

Ferroviário - Por exemplo, se a velocidade deve ser, em determinado trecho, de 20 ou 25 e com a "gambiarra" o trem estiver andando a 40 , o sistema não "penaliza"! Isto quer dizer: o trem não pára. No modo normal do sistema funcionar, se a velocidade imposta não for seguida, for ultrapassada, e, em determinado tempo, o maquinista não reconhecer isto e reduzir a velocidade, o próprio trem vai aplicar emergência e parar! Já com a "gambiarra", o trem continua andando - o sistema avisa, sinalizando (alerta para o excesso de velocidade) mas não penaliza -, quer dizer, o trem não pára.

Entrevistadora - Mas por que será que fazem estas "gambiarras" para o trem correr mais?

Ferroviário - Fazem isso pra colaborar, na verdade. Colaborar com os passageiros e com a Companhia. Mas o dia em que acontece alguma coisa, quem fez a "gambiarra" é responsável porque fugiu das diretrizes da empresa.

Fica evidente a complexidade da questão e o aguçado dilema que traz para o maquinista, que se encontra pressionado por forças tão contraditórias.

O conhecimento da existência de "gambiarras” é difundido nos vários escalões da hierarquia técnica, apesar de ser, como nos disse um supervisor do CCO, "um segredo" sobre o qual os maquinistas evitam geralmente falar com quem não seja de sua estrita confiança. Nunca se estabeleceu um trabalho participativo voltado para discutir a questão e tomar decisões a respeito, embora o problema seja reconhecido como importante fator de quebra da segurança do sistema.

O assunto atinente às infrações de procedimentos prescritos tem estado muito presente nos estudos da Psicodinâmica do Trabalho, tendo sido analisado inclusive nas atividades de uma usina nuclear, em diferentes textos produzidos por Dejours e pesquisadores que com ele trabalharam.

Estes autores analisam de que modo o problema colocado pela distância existente entre o trabalho prescrito e as atividades concretamente desenvolvidas, além de constituir fonte de tensão e sofrimento mental para os trabalhadores, também configura, neste caso, um gravíssimo risco de catástrofe - acidente nuclear. No caso do setor de transportes coletivos, parece-nos que o presente estudo das atividades ferroviárias conduz a conclusões que, de alguma forma aproximam-se das de Dejours. Gera-se um conflito intrapsíquico causado pela neutralização deliberada de um dispositivo de segurança fundamental, e por outro lado, 
gera-se também um real risco de acidente de grandes proporções.

O fato de acidentes ferroviários graves serem bastante raros no histórico recente da empresa, durante a fase de automatização, certamente tende a fortalecer a crença onipotente de que "nada de ruim vai acontecer".

A inquietação despertada por este assunto pode, entretanto, se fazer maior, se voltarmos a atenção para grandes acidentes ferroviários que têm acontecido em outros países que importaram tecnologia, sem que a "modernização" fosse acompanhada de transformações sociais de trabalho e da organização do mesmo.

Como a empresa, valorizando a preservação de sua “imagem veloz", muitas vezes também está submetida a pressões de natureza política que tomam a mesma direção, o desígnio de garantir tal imagem pode ser o escolhido em casos nos quais se coloque para o maquinista o dilema velocidade X maximização de segurança. Tal dilema passa a ser conflito no interior da mente do maquinista, porque o acidente é ainda uma probabilidade, enquanto a rapidez é um fato visível.

Mas quando o acidente ocorre, a situação se transforma subitamente, e então trata-se de apurar responsabilidades: quem optou pela velocidade em detrimento da segurança? Diante de graves prejuízos materiais e, muito especialmente, de vítimas fatais, a análise do acidente apontará os funcionários que, embora sempre tendo feito a escolha da velocidade sem que isto despertasse, pelo menos de modo incisivo, resposta crítica da empresa, defrontar-se-ão agora, pela primeira vez, com os regulamentos e com a apuração dos fatos, em inquéritos formalizados.

\section{A identidade social ante as transformações do trabalho}

A identidade social tem um de seus núcleos na identidade profissional. A profissão exercida é fonte de significados, alimentando os processos de reconhecimento que fundamentam o evolver desta identidade social. Sainsaulieu (1988) assinala e esclarece os processos em que a identidade se transforma, articulada a mudanças tecnológicas e organizacionais. Analisa o quanto as expectativas de mobilidade social ascendente, apoiadas em perspectivas de carreira, podem ser brutalmente estranguladas por transformações técnicas e organizacionais, perante as quais, de modo repentino, determinados grupos profissionais se sentem subitamente marginalizados em face de uma nova onda de progresso para a qual sua formação não os preparou. Diz o citado autor:

"Uma tal situação de marginalidade é fonte de angústia profunda, pois o futuro se torna incerto e o presente totalmente hostil" (p. 193. Tradução nossa).

A questão da identidade também foi estudada nas pesquisas realizadas com ferroviários franceses por Bouvier (1985) e por De la Cruz \& Roche (1990), cujos textos abrem possibilidades para interessantes estudos comparativos que o espaço deste artigo não possibilita discutir.

O estudo brasileiro de Guarido (1981) já havia revelado o quanto a identidade dos maquinistas havia sofrido com impactos negativos ao longo de transformações ocorridas na história da mesma empresa. Guarido constatou que algumas transformações de ordem técnica e, principalmente, as de ordem organizacional, acompanhadas por modificações de valores culturais e da sociabilidade, abalaram mais intensamente a auto-imagem e os projetos de vida. Neste aspecto, as constatações de Guarido confluem bastante com as de De la Cruz \& Roche (1990), que estudaram itinerários de vida e trabalho em maquinistas franceses. A implantação de equipamentos automatizados, nestes casos, como naquele por nós estudado, foi sentida como perda de prestígio e de poder, transformando profundamente o significado do trabalho, pois diminuiu de modo importante a autonomia do maquinista, que, antes de ser submetido ao controle do sistema técnico sofisticado, vivia mais intensamente também o prazer de controlar plenamente seu trem.

Além do orgulho profissional atingido pela nova tecnologia, os maquinistas da empresa estudada também se sentiram alvo de um aumento de controle e de diferentes tipos de repressão. A mágoa pela percepção de falta de reconhecimento por parte das chefias e da empresa foi um sentimento geralmente muito visível nas entrevistas, sendo particularmente intenso nos maquinistas mais antigos da empresa. Por outro lado, além das tensões já mencionadas, vinculadas ao ATC, sentiam-se irritados e fisicamente agredidos pela estridência de um certo dispositivo de alarme que soava com freqüência na cabine do trem.

Nas observações que realizamos em cabine, foi possível perceber a magnitude das exigências de atenção simultânea para diferentes dispositivos técnicos, para a via férrea, para as comunicações via rádio com a sala do CCO, e, às vezes, ainda, para os usuários e portas travadas pelos mesmos.

A má qualidade e a insuficiência do sono foram mencionadas pelos maquinistas entre- 
vistados. Além disso, vários mencionaram o receio de adormecer durante os percursos, considerando que o dispositivo destinado a impedir isto, o famoso "homem morto" - pedal que, se não acionado continuamente, determina alarme seguido por parada do trem -, era de pouca eficácia para impedir o sono.

Na expressão dos entrevistados, entretanto, os problemas decorrentes dos novos dispositivos técnicos e dos horários de trabalho apenas exacerbavam um mal-estar, cuja fonte mais aguda provinha do sentimento de se sentirem injustiçados, e pelo não reconhecimento de seu valor humano e profissional.

Implicações para o estudo e prevenção dos acidentes ferroviários

O avanço tecnológico tem suscitado a difusão de uma imensa idealização, na qual surge a imagem do sistema computadorizado onisciente e perfeito. A imagem é tão poderosa e ao mesmo tempo tão fascinante, que conduz facilmente à ilusão de que a reflexão crítica não pode ser exercida, como se o poder do sistema tivesse ofuscado, reduzido à insignificância o potencial humano de julgamento.

Já mencionamos como se gera, assim, uma dependência do sistema técnico, o que pode conduzir à passividade. Não é mais necessário pensar, abstrações não são valorizadas, uma vez que o sistema tudo pensa, prevê e controla.

Se tal situação é atingida numa fábrica, numa empresa bancária ou em um grande escritório, conforme os estudos de Zuboff (1988), os riscos são, a médio ou longo prazo, para a qualidade e para a competividade. Mas estes riscos se fazem concomitantemente, como já vimos, para a saúde mental.

Nosso estudo leva a refletir que, quando se trata de uma área em que a atividade está voltada para o transporte de massa, algumas outras questões tornam a problemática mais complexa. As questões de segurança, que também existem, por exemplo, na fábrica, tornam-se, entretanto, especialmente aguçadas e visíveis numa atividade em que a responsabilidade referida a milhares de vidas humanas está presente de maneira continuada. A magnitude do cuidado exigido à proteção destas vidas recebe, contudo, uma importante contraposição - a das pressões dirigidas à maximização de velocidade. Tais pressões têm dupla origem, por um lado derivando do interesse da empresa em manter sua imagem de modernidade e eficácia; pelo outro, resultando de exigências dos usuários - que podem inclusive assumir forma de ameaça ou agressão explícita.
A complexidade das contradições emerge, apontando, portanto, em primeiro lugar para uma contradição originada na própria empresa, cujas diretrizes de segurança podem conflitar com as de maximização de rapidez.

Verificamos que as inovações tecnológicas implantadas tinham também por objetivo as duas metas - segurança e rapidez. Diferentes fatores, entretanto, têm conduzido a situações concretas, nas quais é exigida uma opção - segurança ou velocidade. Temendo enfurecer os usuários, os funcionários muitas vezes utilizam habilidades e manhas especiais para favorecer a velocidade.

Acreditamos ser esta uma situação que merece ponderação nas ações voltadas para a prevenção de acidentes ferroviários. Nesta ponderação, merecem ser consideradas as conclusões de pesquisas realizadas principalmente em indústrias que já demonstraram a vantagem existente na implantação de sistemas automáticos flexíveis, nos quais a participação humana é valorizada e a inteligência estimulada, em contraste com os sistemas que conduzem os assalariados à passividade e à dependência (Dina, 1987; Zuboff, 1988).

Uma questão primordial, em nosso meio, certamente é a seguinte: existe, no contexto brasileiro, um problema de falta de confiança entre o topo e a base da pirâmide hierárquica, explicativo para a dificuldade em implantar sistemas nos quais os empregados possuam maior espaço para utilização de sua capacidade de diagnosticar situações e escolher alternativas de ação? Diferentes estudos, especialmente no âmbito da produção brasileira em sociologia do trabalho, parecem indicar uma resposta afirmativa a esta questão. Por outro lado, os fluxos de confiança são também fortemente afetados, em face das incertezas sobre as perspectivas da economia, para o capital e para os assalariados, referentes à continuidade no emprego, e perspectivas quanto a manter ou conquistar qualificação (Hirata, 1993; Mattoso, 1995; Bruno, 1996).

Outra verificação desta pesquisa tem a ver com a constatação de que tanto controladores quanto maquinistas trabalham em condições nas quais a tendência é o acúmulo da fadiga. A introdução dos equipamentos automatizados não foi acompanhada por transformações da organização do trabalho, que protegendo controladores e maquinistas da sobrecarga, da tensão e fadiga excessivas, garantissem melhor a continuidade da manutenção da atenção vigilante.

O "fator humano" tem sido responsabilizado, em geral, no caso dos acidentes ferroviários 
noticiados pela imprensa. Caberia, portanto, aplicar uma consideração melhor às questões que dizem respeito a esse "fator", que, como este estudo procurou mostrar, possui, em verdade, uma complexidade não redutível a essa expressão tão utilizada - "fator humano".

No entanto, não pode ser esquecido que os dispositivos técnicos, quando implantados em condições sócio-políticas, econômicas e administrativas desfavoráveis, estão longe da perfeição sonhada.

\section{Considerações finais}

O conhecimento técnico foi posto ao alcance dos controladores, mas as informações do projeto organizacional sempre foram colocadas distantes do acesso destes profissionais. Assim, os projetos sobre suas próprias carreiras ficaram obscurecidos. A participação em decisões administrativas ficou sempre restrita aos altos escalões.

Para que a inteligência possa manter-se ativa e criativa são necessárias condições psicoafetivas que, por sua vez, fundamentem a "liberdade do pensar" em um clima também propício à geração do comprometimento e do interesse pela atividade desenvolvida e pelas metas da empresa.

Portanto, além do treinamento e da socialização de todas as informações referentes ao processo tecnológico e ao próprio plano de atividades da empresa, cabe cultivar um clima propício à confiança. Para que esta seja obtida, é essencial que também os planos da política de pessoal da empresa tenham transparência.

A confiança será também o solo fértil necessário ao crescimento do interesse e da adesão às atividades. Uma nova dinâmica, entretanto, precisa ser analisada, valendo-se dessa premissa representada pela confiança depositada pelo assalariado sobre a organização. Em primeiro lugar, ele espera uma reciprocidade em termos não só de confiança, mas também em forma de respeito humano. Evidentemente, atuará para favorecer e fortalecer essa confiança, ao mesmo tempo que terá a expectativa de que o respeito por sua essência humana também possa voltar-se para a singularidade do seu ser e de suas aptidões e esforços. Em síntese, o empregado espera ser o alvo de reconhecimento.

Zuboff contrapõe a organização em que a opção foi tornar-se uma instituição de aprendizado continuado com aquelas em que são gastos milhões na compra e instalação de novas tecnologias sem que "nem o mais rudimen- tar treinamento" esteja presente no orçamento anual (p. 89).

"O significado que as pessoas atribuem a seu trabalho, seus níveis de motivação e envolvimento e o tipo de qualificação que possuem vão mediar a relação entre a interface da informação e o observador humano."

Como já mencionamos, a compreensão da dinâmica em que a transformação do trabalho e a identidade se inter-relacionam constitui um alvo central de atenção neste tipo de pesquisa.

Alguns dos trabalhadores entrevistados nos forneceram importantes elementos para analisar tais aspectos.

Um maquinista que trabalhava há 17 anos na empresa expressou como o significado do trabalho foi atingido pelas transformações "modernizadoras", em sua percepção:

"Aqui todo mundo tinha carinho pelo serviço, desde o ajudante até o inspetor de condução, quando eu entrei aqui. Mas isso mudou radicalmente. Não sei exatamente por que. Talvez seja pela modernização. No caso do ATC, por exemplo: ele tirou mais ou menos $50 \%$ da responsabilidade do maquinista. E junto com a responsabilidade tirou a valorização profissional".

Esta fala revela, de modo sintético: a) a percepção de que algo muito valioso, o "carinho pelo serviço", existia e foi perdido; b) a dificuldade de compreender "exatamente por que”; c) a suposição de que a modernização seja a responsável pela perda; d) a idéia de que a modernização se consubstancia na implantação de novos equipamentos (exemplifica com o ATC); e) a percepção de que o equipamento automatizado diminui a "responsabilidade do maquinista”. Em outras palavras, diz que o controle (antes exercido pelo maquinista) foi transferido ao equipamento; f) a interpretação de que esta perda de responsabilidade acarretou perda da "valorização profissional"; g) a subtração da responsabilidade se dá conjuntamente à da valorização.

Como pode ser constatado na análise desta fala, não encontramos nenhuma referência à administração deste trabalho. A interpretação do entrevistado é a de uma relação direta e inexorável estabelecida entre uma modernização - que é representada, aqui, tão somente pela implantação de equipamento automatizador e a perda conjunta de responsabilidade e valor.

Por um lado, é compreensível que o papel da administração, ou mais especificamente, o planejamento do trabalho e a forma pelo qual ele é controlado/avaliado, esteja ausente da fala, muito embora o maquinista deixe esboçada a percepção de um mistério, de algo não intei- 
ramente inteligível ("Não sei exatamente por que. Talvez seja pela modernização.”).

Acreditamos que a não-alusão aos responsáveis pela direção e administração da empresa por ocasião das pesquisas se deve essencialmente a dois aspectos:

1) A clivagem verificada, nesta empresa, entre planejamento/execução é de tal modo absoluta que resulta na invisibilização, para o executante do trabalho (o maquinista, no caso), de que o "esvaziamento", percebido no valor de sua atividade, faz parte de uma opção organizacional.

2) De fato, com a introdução do novo equipamento, nada foi acrescentado ao maquinista que o fizesse sentir que seu valor profissional foi preservado ou acrescentado. Em suma: não houve manifestação perceptível de que existisse uma instância (de gestão e organização do trabalho) onde ele, maquinista, tivesse sido considerado sujeito no processo de trabalho, ser pensante e que precisaria manter uma interlocução com os planejadores do trabalho para definir seu novo papel e suas próprias observações e sugestões de ação, perante a implantação dos equipamentos de tecnologia avançada.

Feitas estas considerações, resta ainda a seguinte: o maquinista estabeleceu uma relação entre o "carinho pelo serviço" e a "valorização profissional”, que é de plena identidade. Ou melhor - no encadeamento de sua reflexão, ele toma o carinho como ponto de partida, representando o que havia de precioso e foi perdido; fala a seguir da modernização e do novo equipamento, para dizer que pensa que a perda se fez em termos de responsabilidade e valorização profissional. Então, responsabilidade e valorização profissional se constituem componentes essenciais daquilo que constrói o carinho pelo serviço. E acreditamos que este carinho pelo serviço seja exatamente aquilo que a administração voltada para a busca da qualidade tanto procura - adesão e compromisso -, em que o significado e o afeto estão envolvidos intimamente.

O que o maquinista nos disse foi que sentiu que algo precioso lhe foi subtraído. Não visualizou que poderia não ter sido assim, que ele e seu carinho pelo serviço poderiam ter sido enriquecidos, ao invés de desvalorizados, se lhe tivesse sido dado o acesso a participar da "modernização" como sujeito ativo e não como profissional que vê sua experiência prática ser substituída por equipamentos e, assim, menosprezada.

Concluímos aqui, constatando que a desvalorização que fez este entrevistado sentir-se desqualificado é a mesma que atinge a identidade de tantos outros em nosso tempo, acionando sofrimentos e patologias para os trabalhadores, ao mesmo tempo que retardando, para empresas e para países, a mudança modernizadora real e significativa - só alcançável se, além da implantação de novos equipamentos, for implantada uma nova forma de integrar o ser humano ao trabalho, nele podendo cultivar seu prazer e seus valores essenciais. 


\section{Referências}

AUBERT, N. \& GAULEJAC, V., 1991. Le Cout de l'Excelence. Paris: Seuil.

BÖHLE, F. \& MILKAU, B., 1988. Vom Handrad zum Bildschirm-Eine Untersuchung zur zinnlichen Erfahrung im Arbeitsprozess. Munique: Campus Verlag.

BOUVIER, P., 1985. Technologie, Travail, Transports. Paris: Librairie des Meridiens.

BRUNO, L., 1996. Educação e Trabalho no Capitalismo Contemporâneo. São Paulo: Atlas.

DE LA CRUZ, M. \& ROCHE, P., 1990. Trains de Vie. Marselha: Ed. Matrice.

COLLINS, R. T., 1969. Occupational Psychiatry. Boston: Little Brown and Co.

DEJOURS, C.,1993. Travail, Usure Mentale. Paris: Ed. Bayard.

DEJOURS, C., 1995. Le Facteur Humain. Paris: Presses Universitaires de France (PUF).

DEJOURS, C.; ABDOUCHELI, E. \& JAYET, C., 1994. Psicodinâmica do Trabalho. São Paulo: Atlas.

DINA, A., 1987. A Fábrica Automática e a Organização do Trabalho. Petrópolis: Ed. Vozes.

ELIAS, N., 1995. Technization and civilization. Theory, Culture and Society, 12(13):7-42.

FERNANDES, S. R. P., 1992. Trabalho Informatizado e Distúrbios Psicoemocionais: Estudo Seccional em Três Empresas de Processamento de Dados em Salvador. Dissertação de Mestrado, Salvador: Faculdade de Medicina, Universidade Federal da Bahia.

FISCHER, F. M., 1990. Condições de Trabalho e de Vida em Trabalhadores do Setor Petroquímico. Tese de Livre-Docência, São Paulo: Faculdade de Saúde Pública, Universidade de São Paulo.

FORET, J., 1987. Conditions de travail des conducteurs de trains: revue des études physiologiques e psychophysiologiques. Le Travail Humain, 50:1734

FERRETTI, C. J.; ZIBAS, D. M. L.; MADEIRA, F. R. \& FRANCO, M. L. P. B., 1994. Tecnologias, Trabalho e Educação - Um Debate Multidisciplinar. Petrópolis: Vozes.

GUARIDO, E. L., 1981. Percepção de Controle sobre o Trabalho em um Grupo de Ferroviários. Dissertação de Mestrado, Campinas: Faculdade de Psicologia, Pontifícia Universidade Católica.

HIRATA, H., 1993. Sobre o Modelo Japonês. São Paulo: Edusp.

JARDIM, S., 1994. Processo de Trabalho e Sofrimento Psíquico: O Caso dos Pilotos do Metrô Carioca. Tese de Doutorado, Rio de Janeiro: Instituto de Psiquiatria, Universidade Federal do Rio de Janeiro.

JINKINGS, N., 1995. O Mister de Fazer Dinheiro: Automatização e Subjetividade no Trabalho Bancário. São Paulo: Bomtempo Editorial.

LOJKINE, J., 1995. A Revolução Informacional. São Paulo: Cortez Editora.

MARSTEDT, G., 1994. Rationalisierung und Gesundheit Berlin. Berlin: WZB - Wissenschaftszentrum Berlin für Sozialforschung-Forschungsgruppe Gesundheitsrisiken und Präventionspolitik. Paper: P94-204.
MARTY, P., 1976. Les Mouvements Individuels de Vie et de Mort. Paris: Payot.

MARTY, P., 1980. L'Ordre Psychosomatique: Les Mouvements Individuels de Vie et de Mort. Vol. 2, Paris: Payot.

MATRAJT, M., 1994. Estudios en Salud Mental Ocupacional. Texcoco. Mexico: Ed. Taller Abierto.

MATTOSO, J., 1995. A Desordem do Trabalho. São Paulo: Scritta.

MEDEIROS, G., 1995. As organizações e a desconstrução da subjetividade. In: A Falência Psicológica nas Organizações (T. Furtado, org.), pp. 6-25, Rio de Janeiro: Editoração.

REBECCHI, E., 1990. O Sujeito Frente à Inovação Tecnológica. Petrópolis: Vozes/IBASE.

ROCHA, L. E., 1989. Tenossinovite como Doença do Trabalho no Brasil. Dissertação de Mestrado, São Paulo: Faculdade de Medicina, Universidade de São Paulo.

ROCHA, L. E., 1996. Estresse Ocupacional em Profissionais de Processamento de Dados: Condições de Trabalho e Repercussões na Vida e Saúde dos Analistas de Sistemas. Tese de Doutorado, São Paulo: Faculdade de Medicina, Universidade de São Paulo.

SAINSAULIEU, R., 1988. L'Identité au Travail. Paris: Presses de la Fondation Nationale des Sciences Politiques.

SELIGMANN-SILVA, E., 1994. Desgaste Mental no Trabalho Dominado. Rio de Janeiro/ São Paulo: Editora da Universidade Federal do Rio de Janeiro/Cortez.

SELIGMANN-SILVA, E., 1995a. Psicopatologia e psicodinâmica do trabalho. In: Patologia do Trabalho (R. Mendes, org.) pp. 287-310, Rio de Janeiro: Ed. Ateneu.

SELIGMANN-SILVA, E., 1995b. Os riscos da insensibilidade. In: Recursos Humanos: A Falência Psicológica nas Organizações (T. Furtado, org.), pp.63-87, Rio de Janeiro: Editoração Ltda.

SELIGMANN-SILVA, E.; DELÍA, A. A. \& SATO, L., 1985 Saúde Mental dos Bancários. São Paulo: DIESAT. Relatório de Pesquisa (mimeo.).

SELIGMANN-SILVA, E.; DELÍA, A. A. \& SATO, L., 1986 A Saúde na Área Operativa do Metrô de S.Paulo. São Paulo: DIESAT/Sindicato dos Metroviários. Relatório de pesquisa (mimeo.).

SILVA FILHO, J. F. E., 1994. Organização do Trabalho e Saúde Mental: Estudo das Relações entre a Prevalência de Doenças Mentais e Organização do Trabalho Bancário no Municipio do Rio de Janeiro. Textos para Discussão n.7. Rio de Janeiro: Instituto de Psiquiatria, Universidade Federal do Rio de Janeiro.

TITTONI, J., 1994. Subjetividade e Trabalho. Porto Alegre: Ortiz Editora.

ZUBOFF, S., 1988. In the Age of the Smart Machine. New York: Basic Books. 